\title{
Prognosis of Guillain-Barré syndrome in the African: the Nigerian experience
}

\author{
BENJAMIN O. OSUNTOKUN AND KOFO AGBEBI
}

From the Neurology Unit, Department of Medicine, University College Hospital, Ibadan, Nigeria

SUMMARY The clinical features of the Guillain-Barré syndrome in 34 Nigerian patients are reported. The patients were treated with oral prednisolone $20 \mathrm{mg}$ three times daily for a minimum of six weeks. Twenty-seven patients recovered completely and five others showed considerable improvement, although three of them appeared to be 'steroid dependent'. Two patients died. The good prognosis and the response to treatment with prednisolone in this series is in keeping with an allergic demyelinating neuropathy.

The Guillain-Barré syndrome (GBS), or acute infective polyneuropathy, is now accepted to be the clinical prototype of experimental allergic neuritis as described by Waksman and Adams $(1955,1956)$. In the pathogenesis of the experimental condition cell-mediated allergic phenomena or autoimmune processes occur (Asbury and Arnason, 1968; Astrom, Webster, and Arnason, 1968; Knowles, Saunders, Currie, Walton, and Field, 1969; Caspary, Currie, Walton, and Field, 1971; Currie and Knowles, 1971; Rocklin, Sheremata, Feldman, Kies, and David, 1971). In both disorders the proximal parts of the spinal (and cranial nerves) are predominantly involved, resulting in oedema, swelling, and irregularity of the myelin sheaths and axis cylinders and accompanied by lymphocytic cellular infiltration, segmental demyelination, and axonal degeneration (Haymaker and Kernohan, 1949; Asbury, Arnason, and Adams, 1969; Wiśniewski, Terry, Whitaker, Cook, and Dowling, 1969). Antecedent infections may play a major role in producing antigenic stimulation of antibodies against nervous tissue (Melnick and Flewett, 1964). This is further supported by the high frequency of antecedent infections or febrile illness days or usually weeks before the onset of the GBS (Haymaker and Kernohan, 1949; Marshall, 1963; Wiederholt, Mulder, and Lambert, 1964). In most developing African countries, the prevalence of infectious diseases is high. On the other hand, it is now being increasingly realized that autoimmune diseases such as Hashimoto's thyroiditis, pernicious anaemia, the collagen diseases and myasthenia gravis are uncommon or rare, at least in Nigerians (Greenwood, 1968; Osuntokun, 1971a). The Guillain-Barré syndrome has also been reported to be rare in Negroes (Haymaker and Kernohan, 1949), although in more recent times this appears to be untrue (Massuci and Kurtzke, 1971). It is against this background that we wish to report this series of Nigerian patients who suffered from the syndrome and their response to treatment with prednisolone.

\section{METHODS}

The series comprised 34 Nigerian patients admitted into the wards of University College Hospital (U.C.H.), Ibadan, Nigeria, between 1960 and 1971; 19 of these patients were seen in the last six years and evaluated by one of us (B.O.O.). In the same period about 280,000 patients were admitted into the wards of U.C.H., Ibadan, and approximately 60,000 are seen annually in the outpatient clinics of the hospital.

Criteria for diagnosis were essentially the same as those of Osler and Sidell (1960), and in summary comprise:

1. Acute onset of sensory, motor, or sensorimotor more or less symmetrical polyneuropathy, with or without antecedent febrile illness, upper respiratory infection, or diarrhoea.

2. Demonstrable cytoalbuminological dissociation in the cerebrospinal fluid (CSF). 
3. Exclusion of other causes of peripheral polyneuropathy, especially those associated with cytoalbuminological dissociation in CSF, such as diabetic and carcinomatous neuropathy, and other neuropathies secondary to known systemic, toxic, and metabolic diseases, malnutrition, and recent immunizations.

\section{RESULTS}

AGE AND SEX Distribution See Table 1. The peak frequency was in the second decade of life. There was a slight male preponderance (male to female ratio was approximately $7: 5$ ), but males normally predominate in the hospital population in U.C.H., Ibadan, the male to female ratio being $3: 2$. In the eight patients below the age of 15 years, the onset of symptoms was in no way related to recent immunization.

TABLE 1

AGE AND SEX DISTRIBUTION OF NIGERIAN PATIENTS WITH GUILLAIN-BARRÉ SYNDROME

\begin{tabular}{|c|c|c|c|c|c|c|c|}
\hline & \multicolumn{6}{|c|}{ Age (yr) } & \multirow[t]{2}{*}{ Total } \\
\hline & $0-9$ & $10-19$ & $20-29$ & $30-39$ & $40-49$ & $50-59$ & \\
\hline Male & 1 & 6 & 4 & 3 & 3 & 3 & 20 \\
\hline Female & 3 & 4 & i & 3 & 2 & 1 & 14 \\
\hline Total & 4 & 10 & 5 & 6 & 5 & 4 & 34 \\
\hline
\end{tabular}

SOCIOECONOMIC STATUS Patients were found in all the socioeconomic groups, with no clear-cut predilection for any group.

ANTECEDENT ILLNESS See Table 2. The duration of the antecedent illness before onset of neurological symptoms varied from two days to three weeks, with a mean of two weeks. None of the patients with a history of preceding febrile illness was pyrexial on admission. None of our patients kept pets such as cats and dogs.

SEASONAL VARIATION There was no particular bias for any part of the year, the cases being uniformly distributed throughout the year.

CLINICAL NEUROLOGY All patients were seen in hospital within three weeks of the appearance of neurological symptoms.
TABLE 2

ANTECEDENT ILLNESS IN NIGERIANS WITH GUILLAIN-BARRÉ SYNDROME

\begin{tabular}{lrc}
\hline Antecedent illness & No. & $\%$ of total \\
\hline Non specific pyrexial illness & 11 & 33 \\
Upper respiratory tract infections & 4 & 12 \\
Diarrhoea & 1 & 3 \\
\hline Total & 16 & 48 \\
\hline
\end{tabular}

The presenting symptoms are shown in Table 3. Usually symptoms began in lower limbs, and paraesthesiae and/or dysaesthesiae when present, preceded by hours or one or two days the onset of weakness or heaviness of limbs. Weakness progressed over a period of more than three days, with a range of three to seven and a mean of five days. By the time of admission, 15 of the patients were unable to walk because of paralysis, and five complained of severely ataxic gait. Six patients complained of dysphagia for solids and liquids, one of dyspnoea, and two of vertigo. Four patients were incontinent for urine and faeces, and two others complained of hesitancy of micturition and constipation.

The physical signs are as shown in Table 4. Flaccid weakness of all limbs was present in 20 patients and 10 of these were unable to walk.

TABLE 3

NEUROLOGICAL SYMPTOMS ON ADMISSION IN 32 NIGERIANS WITH GUILLAIN-BARRÉ SYNDROME

\begin{tabular}{|c|c|c|}
\hline Symptoms & & No. \\
\hline $\begin{array}{l}\text { Paraesthesiae or dysaest } \\
\text { in all limbs } \\
\text { in lower limbs only } \\
\text { in upper limbs only }\end{array}$ & $\begin{array}{l}\text { hesiae } \\
9 \\
6 \\
2\end{array}$ & 17 \\
\hline $\begin{array}{l}\text { Weakness } \\
\text { in all limbs } \\
\text { in lower limbs only } \\
\text { in upper limbs only }\end{array}$ & $\begin{array}{r}20 \\
9 \\
2\end{array}$ & 31 \\
\hline \multicolumn{2}{|c|}{$\begin{array}{l}\text { Symptoms of cranial neuropathy } \\
\text { (diplopia, ptosis, ageusia, dysphagia, } \\
\text { impaired vision, hoarseness, dysphonia, } \\
\text { paraesthesiae in face, etc.) }\end{array}$} & 10 \\
\hline $\begin{array}{l}\text { Symptoms of sphincteric } \\
\text { faecal and urinary } \\
\text { incontinence } \\
\text { hesitancy }\end{array}$ & $\begin{array}{l}\text { dysfunction } \\
4 \\
2\end{array}$ & 6 \\
\hline
\end{tabular}


TABLE 4

PHYSICAL SIGNS ON ADMISSION IN 32 NIGERIANS WITH GUILLAIN-BARRÉ SYNDROME

\begin{tabular}{lc}
\hline Signs & No. \\
\hline Flaccid weakness & 31 \\
Sensory loss & 24 \\
Tendon areflexia/hyporeflexia & 32 \\
Cranial neuropathies & 10 \\
Nystagmus & 2 \\
Palpable bladder & 4 \\
Lax anal sphincter & 4 \\
Respiratory paralysis & 2 \\
Skin rash & 1 \\
Muscle tenderness & 1 \\
\hline
\end{tabular}

Flaccid weakness was present, in the lower limbs only, in nine patients, five of whom were unable to walk. In two patients mild flaccid weakness (grade 3-4 MRC scale) was present in the upper limbs only. The proximal musculature of the limbs was more severely affected than the distal musculature in only two patients; in 18 patients, the distal musculature was more severely affected and, in 11 other patients, both the distal and proximal musculature of the limbs were equally weak. About half of the patients showed demonstrable (though often slight) wasting of the weak muscles. None showed fasciculations. Muscle tenderness was severe in two patients.

Superficial sensations (light touch, pain, and temperature) were lost in three patients, deep sensations (vibration perception, appreciation of joint movement), were lost in two patients, and both superficial and deep sensations were lost in 19 patients. Superficial sensory loss was usually of the 'glove and stocking' distribution. Sensory loss was usually associated with muscular weakness, except in three patients who had superficial sensory loss in the lower limbs unassociated with any muscular weakness. In nine patients sensory loss was confined only to the lower limbs.

Tendon areflexia or hyporeflexia was found in the upper limbs alone in two patients, in the lower limbs alone in nine patients, and in all limbs in 21. Tendon reflex status was normal in two patients who had mild muscular weakness without any sensory loss.

A single cranial nerve lesion was present in two patients (unilateral oculomotor palsy in one, and unilateral facial infranuclear palsy in another) in association with sensorimotor polyneuropathy of the limbs. Eight other patients with involvement of the limbs showed neuropathy of more than one cranial nerves. The frequency of cranial nerve lesions in this series is shown in Table 5. Lesions of the trigeminal, facial, glossopharyngeal, and vagus nerves were usually bilateral. In two patients in whom multiple cranial nerve palsies were present the involvement on both sides was asymmetrical.

TABLE 5

CRANIAL NERVE LESIONS IN NIGERIANS WITH GUILLAIN-BARRÉ SYNDROME

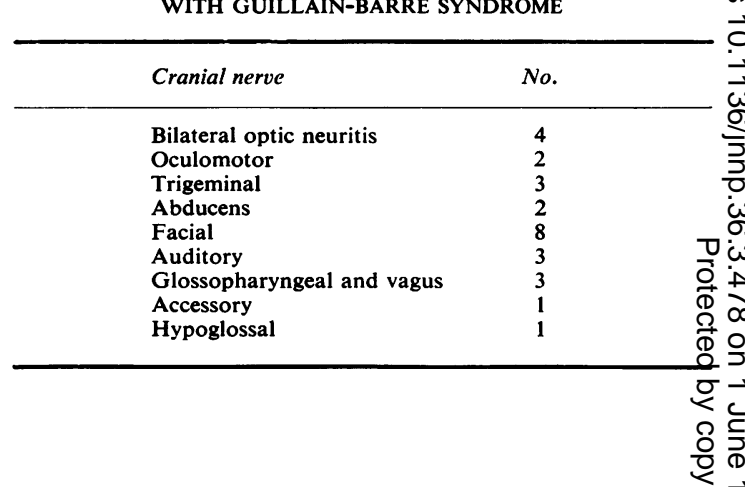

Eight patients were judged to show definit $\overrightarrow{0}$ demonstrable cerebellar ataxia (especially in the upper limbs), as shown by intention and static tremor, adiadochokinesia, or rebound phenomenon.

In four patients, a distended bladder with overflow incontinence and lax anal sphincter was found. In another patient with intractable constipation, impacted faeces in the rectum were manually evacuated with considerable difficulty. None of our patients showed other evidence of autonomic dysfunction such as tachycardia, hypertension, hypotension, and excessive sweating.

One patient had an episode of generalized convulsions on admission.

Two patients were in respiratory failure on $\bigcirc$ admission; in one of them it was severe enough $\rightarrow$ to require emergency application of assisted respiration (intermittent positive pressure respira- N tion with cuffed tracheostomy).

Of the 34 patients in this series, 10 had a pure motor neuropathy. 
CSF EXAMINATION Twenty-five of the patients showed cytoalbuminological dissociation (raised protein concentration and normal cell count). In seven of these patients, cytoalbuminological dissociation was demonstrable only in a repeat examination of CSF two to three weeks after the first examination of CSF on admission. In these 25 patients the range of protein concentration in CSF was $80-1,000 \mathrm{mg} / 100 \mathrm{ml}$. with a mean of $150 \mathrm{mg} / 100 \mathrm{ml}$.

In nine patients, no cytoalbuminological dissociation was demonstrable; four of these had at least two examinations of CSF at not less than two week intervals.

The CSF of nine patients with cytoalbuminological dissociation was examined three weeks after treatment started with prednisolone. In two patients the CSF protein had returned to normal. There was no correlation between CSF protein concentration and rapidity of clinical recovery.

OTHER INVESTIGATIONS Two patients showed a positive Kahn test in blood and CSF, in low titres, and were presumed to have suffered from yaws previously, especially as they recovered fully after treatment with prednisolone.

In one patient leucocytosis was present with a white cell count of 19,500 per c.mm, $47 \%$ of which were lymphocytes. However, the morphology of the lymphocytes did not suggest infectious mononucleosis and the Paul-Bunnell test was negative.

Electromyography usually confirmed neurogenic atrophy, but without any evidence of spontaneous activity. The determination of nerve conduction velocity as described elsewhere (Osuntokun, 1968) in 14 patients did not give consistent results. In eight of the patients whose illness had lasted more than three weeks at the time the investigation was done, motor nerve conduction velocity was considerably reduced (to below $20 \mathrm{~m} / \mathrm{sec}$ in the ulnar, median, and common peroneal nerves), suggestive of segmental demyelination. In three of these patients, biopsy of the anterior tibial nerve showed segmental demyelination in single nerve fibre preparation by the method of Visozo and Young (1948) and Thomas and Lascelles (1965). In six patients with a short duration of illness (of less than two weeks) motor nerve conduction velocity was normal.

TREATMENT Patients were treated with oral prednisolone $20 \mathrm{mg}$ three times daily for a minimum of six weeks. After six weeks of treatment, the dosage of prednisolone was then progressively reduced and stopped. Drug treatment was supplemented by physiotherapy and active rehabilitative exercises.

OUTCOME One patient who required intermittent positive pressure respiration was in hospital for six months, but eventually recovered enough to be able to walk on discharge. Twentyseven patients recovered completely. Two patients showed no improvement after eight weeks of treatment with prednisolone; drug treatment was then stopped. Three patients who initially responded to treatment with prednisolone relapsed when attempts were made to wean them off prednisolone: these patients improved when treatment with prednisolone was reinstituted and had to be maintained for three, six, and nine months on daily doses of 5 to $10 \mathrm{mg}$ prednisolone. They were, however, eventually weaned off prednisolone without relapse. Two patients died rather suddenly and clinically appeared to have suffered from massive pulmonary embolism, although necropsy was not performed.

\section{DISCUSSION}

Acute infective polyneuritis, or the GuillainBarré syndrome (GBS), constitutes at U.C.H.Ibadan, $0.012 \%$ of hospital admissions (Osuntokun, 1971b). The incidence in the hospital population is 2 per 15,000 . It is, therefore, not a common disease in Nigerians and has the same prevalence rate and incidence as muscular dystrophies and polymyositis (Osuntokun, 1971b). In Nigerians, however, GBS occurs in higher frequency than other conditions accepted as autoimmune diseases-such as myasthenia gravis, disseminated lupus erythematosus, Hashimoto's thyroiditis, and pernicious anaemia; the last two are virtually unknown in Nigerians.

Although in the Nigerian environment, febrile illnesses are commoner in the wet season, May to October, the distribution of our cases did not reflect any clear evidence of a seasonal incidence. 
In different environments, Haymaker and Kernohan (1949), in the United States, and Marshall (1963), in Britain, arrived at the same conclusion, although slightly fewer cases were seen in the months June to September than during the rest of the year. Melnick and Flewett (1964), in Britain, reported a higher frequency of the disease in the first half of the year especially in February and June, than in the second half of the year.

The clinical neurology of the disease in Nigerians is similar to that described in other races. It is worth emphasizing, however, the frequency of pure motor neuropathy (in nearly one-third of the patients) and of cerebellar ataxia (in nearly one-quarter of the patients). Sphincteric disturbance was present in nearly one-sixth of the patients in this series-a rather high frequency. Marshall (1963) has previously emphasized the importance of repeated CSF examination, if necessary, to demonstrate cytoalbuminological dissociation, an opinion further supported by our findings.

It is now well established that the lesion in GBS is segmental demyelination and that this initially affects the proximal parts of the peripheral nerves near the spinal cord (Haymaker and Kernohan, 1949). Hence, in cases seen early, nerve conduction velocity in the more peripheral parts of the nerves would be expected to be normal. In the later stages, segmental demyelination spreads to the peripheral parts of the nerves and slowing of nerve conduction velocity may be present. These concepts are partially supported by our findings.

The good prognosis and the response to treatment with prednisolone in our series is in keeping with an allergic demyelinating neuropathy in which the percentage recovery can be as high as $50 \%$ or higher (Graveson, 1961; Simpson, 1962; Eiben and Gersony, 1963), although in our series the percentage recovery is much higher $(94 \%)$. A few patients, however, appeared to be transiently steroid-dependent, a well-recognized phenomenon in some types of peripheral neuropathy (Austin, 1958; Matthews, Howell, and Hughes, 1970) and especially in the chronic form of GBS. Although Guillain (1936) emphasized the favourable prognosis, the good response of Nigerian patients in this series is worthy of note, as only recently it was stated that "corticosteroid treat- ment has not given much benefit in the acute syndrome' of Guillain-Barré (British Medical Journal, 1971). It should be recalled, however, that in Marshall's (1963) series, of the 28 patients who made a complete recovery, 11 received corticosteroids and $\mathbf{1 7}$ did not. It is unlikely that the good prognosis in our patients is related to the relatively short interval between the onset of neurological illness and the preceding febrile illness. Ravn (1967) found that the interval had no effect on the later course of patients with the disease. The longest interval in his series of 127 patients was 45 days. Similarly, Pleasure, Lovelace, and Duvoisin (1968), accepting cases with an interval of up to two months, found no difference in prognosis between those with a shorter and those with a longer interval. In this series, the interval did not exceed three weeks. None of our patients was, however, treated with immunosuppressive drugs such as methotrexate, 6-mercaptopurine, and azathioprine-drugs which have occasionally been claimed to achieve remarkable therapeutic success in the treatment of GBS (Palmer, 1965; Yuill, Swinburn, and Liversedge, 1970). It is possible that the good $\mathbb{D}$ prognosis in Nigerian patients suffering from the GBS may be related to the beneficial modification of the immune response of Nigerians by응 the presence of multiple parasitic infections. Another autoimmune disease, rheumatoid arthritis, has a good prognosis in Nigerians (Greenwood, 1969). Although two of our patients died, none died directly from the effects of GBS. This agrees with the experience of others (Osler and Sidell, 1960; Eiben et al., 1963). The good prognosis as seen in the patients in this series makes it imperative to control respiration if bulbar or thoracic paralysis is present.

\section{REFERENCES}

Asbury, A. K., and Arnason, B. G. (1968). Experimental allergic neuritis: a radioautographic study. Journal of Neuropathology and Experimental Neurology, 27, 581-590. Asbury, A. J., Arnason, B. G., and Adams, R. D. (1969). The inflammatory lesion in idiopathic polyneuritis. Its role in pathogenesis. Medicine, 48, 173-215.

Aström, K. E., Webster, H. de F., and Arnason, B. G. (1968). The initial lesion in experimental allergic neuritis. A phase and electron microscopic study. Journal of Experimental Medicine, 128, 469-495.

Austin, J. H. (1958). Recurrent polyneuropathies and their corticosteroid treatment. Brain, 81, 157-192.

British Medical Journal (1971). Leader: Relapsing polyneuropathy and corticosteroids. British Medical Journal, 1, 62-63. 
Caspary, E. A., Currie, S., Walton, J. N., and Field, E. J. (1971). Lymphocyte sensitization to nervous tissues and muscle in patients with the Guillain-Barré syndrome. Journal of Neurology, Neurosurgery, and Psychiatry, 34, 179-181.

Currie, S., and Knowles, M. (1971). Lymphocyte transformation in the Guillain-Barré syndrome. Brain, 94, 109-116.

Eiben, R. M., and Gersony, W. M. (1963). Recognition, prognosis and treatment of the Guillain-Barré syndrome (acute idiopathic polyneuritis). Medical Clinics of North America, 47, 1371-1380.

Graveson, G. S. (1961): The use of steroids in the treatment of the Guillain-Barré syndrome. Proceedings of the Royal Society of Medicine, 54, 575-576.

Greenwood, B. M. (1968). Autoimmune disease and parasitic infections in Nigerians. Lancet, 2, 380-382.

Greenwood, B. M. (1969). Acute tropical polyarthritis. Quarterly Journal of Medicine, 38, 295-306.

Guillain, G. (1936). Radiculoneuritis with acellular hyperalbuminosis of the cerebrospinal fluid. Archives of Neurology and Psychiatry (Chic.), 36, 975-990.

Haymaker, W., and Kernohan, J. W. (1949). The LandryGuillain-Barré syndrome. Medicine, 28, 59-141.

Knowles, M., Saunders, M., Currie, S., Walton, J. N., and Field, E. J. (1969). Lymphocyte transformation in the Guillain-Barré syndrome. Lancet, 2, 1168-1170.

Marshall, J. (1963). The Landry-Guillain-Barré syndrome. Brain, 86, 55-66.

Masucci, E. F., and Kurtzke, J. F. (1971). Diagnostic criteria for the Guillain-Barré syndrome: an analysis of 50 cases. Journal of Neurological Science, 13, 483-501.

Matthews, W. B., Howell, D. A., and Hughes, R. C. (1970). Relapsing corticosteroid-dependent polyneuritis. Journal of Neurology, Neurosurgery, and Psychiatry, 33, 330-337.

Melnick, S. C., and Flewett, T. H. (1964). Role of infection in the Guillain-Barré syndrome. Journal of Neurology, Neurosurgery, and Psychiatry, 27, 395-407.

Osler, L. D., and Sidell, A. D. (1960). The Guillain-Barré syndrome. New England Journal of Medicine, 262, 964-969.

Osuntokun, B. O. (1968). An ataxic neuropathy in Nigeria. A clinical, biochemical and electrophysiological study. Brain, 91, 215-248.

Osuntokun, B. O. (1971a). Relationship as a clue to causation. Lancet, 1, 647-648.
Osuntokun, B. O. (1971b). The pattern of neurological illness in tropical Africa: experience at Ibadan, Nigeria. Journal of Neurological Sciences, 12, 417-442.

Palmer, K. N. V. (1965). Polyradiculoneuropathy (GuillainBarré syndrome) treated with 6-mercaptopurine. Lancet, 1, 733-734.

Pleasure, D. E., Lovelace, R. E., and Duvoisin, R. C. (1968). The prognosis of acute polyradiculoneuritis. Neurology (Minneap.), 18, 1143-1148.

Ravn, H. (1967). The Landry-Guillain Barré syndrome. Acta Neurologica Scandinavica, 43, Whole Suppl. 30.

Rocklin, R. E., Sheremata, W. A., Feldman, R. G., Kies, M. W., and David, J. R. (1971). The Guillain-Barré syndrome and multiple sclerosis: in vitro cellular responses to nervous-tissue antigens. New England Journal of Medicine, 284, 803-808.

Simpson, J. A. (1962). The neuropathies. In Modern Trends in Neurology, 3, pp. 261-264. Edited by D. Williams. Butterworths: London.

Thomas, P. K., and Lascelles, R. G. (1965). Pathology of diabetic neuropathy. Lancet, $1,1355-7$.

Visozo, A. D., and Young, J. Z. (1948). Internodal length and fibre diameter in developing and regenerating nerves. Journal of Anatomy. 82, 110-134.

Waksman, B. H., and Adams, R. D. (1955). Allergic neuritis: an experimental disease of rabbits induced by injection of peripheral nervous tissue and adjuvants. Journal of Experimental Medicine, 102, 213-236.

Waksman, B. H., and Adams, R. D. (1956). Symposium on peripheral neuropathies; comparative study of experimental allergic neuritis in rabbit, guinea pig, and mouse. Journal of Neuropathology and Experimental Neurology, 15, 293-333.

Wiederholt, W. C., Mulder, D. W., and Lambert, E. H. (1964). The Landry-Guillain-Barré-Strohl syndrome or polyradiculoneuropathy. Mayo Clinic Proceedings, 39, 427-451.

Wiśniewski, H., Terry, R. D., Whitaker, J. N., Cook, S. D., and Dowling, P. C. (1969). Landry-Guillain-Barré syndrome: a primary demyelinating disease. Archives of Neurology (Chic.), 21, 269-276.

Yuill, G. M., Swinburn, W. R., and Liversedge, L. A. (1970). Treatment of polyneuropathy with azathioprine. Lancet, 2 , 854-856. 